\title{
Estratégia de resistência em interlocução com a Divisão Sexual do Trabalho: 0 diferencial feminino com vistas a romper as barreiras de gênero
}

Resistance strategy in dialogue with the Sexual Division of Labor: the female differential with a view to breaking down gender barriers

Raquel Quirino ${ }^{1}$ Bruna de Oliveira Gonçalves ${ }^{2}$

1 Centro Federal de Educação Tecnológica de Minas Gerais, Departamento de Educação, Brasil, E-mail: quirino.raquel@hotmail.com, ORCID: https://orcid.org/0000-0000-9256-656X

2 Universidade Federal de Minas Gerais, Centro de Apoio à Educação a Distância, Brasil, E-mail: brunadogoncalves@gmail.com, ORCID: https://orcid.org/0000-0002$\underline{6787-1914}$

A R T I C L E I N F O

Article history:

Received 2021-06-03

Accepted 2021-06-29

Available online 2021-06-30
Palavras-chave: Divisão Sexual do Trabalho. Estratégia de resistência. Diferencial de gênero.

Keywords: Sexual Division of Labour. Resistance Strategy. Gender diferential.

RESUMO. A Constituição de 1988 representou avanços importantes às mulheres no que diz respeito às garantias legais e abriu caminhos para que outros aparatos jurídicos fossem criados com vistas à equidade de gênero no Brasil. Em se tratando do trabalho, no entanto, as teorias da Divisão Sexual do Trabalho postulam, com seus princípios organizadores, que existem trabalhos de homens e trabalhos de mulheres e, aquele executado por eles tem valor superior ao que elas realizam. Frente às injustiças de gênero anunciadas pela literatura científica, confirmadas em dados estatísticos e nos discursos de várias trabalhadoras investigadas, as mulheres não aceitam passivamente a realidade que as coloca na posição de desprestígio, mobilizando, assim, diversas estratégias de luta e resistência. Neste artigo, as falas de diferentes mulheres, sujeitos de pesquisas de pós-graduação stricto sensu, evidenciam que as mulheres desenvolvem um diferencial para que consigam oportunidades minimamente mais próximas às concedidas aos homens no mundo do trabalho. Destarte, por ser um movimento de importância inestimável para a redução das desigualdades, urge que a sociedade avance no sentido de que as exigências profissionais que recaem sobre as mulheres sejam as mesmas que atingem os homens, bem como a divisão justa das tarefas domésticas e a valorização equânime da força de trabalho de ambos.

ABSTRACT. The 1988 Brazilian Constitution represented important advances for women regarding legal guarantees and opened paths for other legal apparatuses to be created to gender equality in Brazil. When it comes to work, however, the theories 
of the Sexual Division of Labor postulate, with their organizing principles, that there are men's work and women's work, and that performed by men's has a higher value than what women's do. Faced with the gender injustices announced in the scientific literature, confirmed in statistical data and in the speeches of several investigated workers, women do not passively accept the reality that puts them in a position of discredit, thus mobilizing various strategies of struggle and resistance. In this article, the speeches of different women, subjects of stricto sensu graduate research, show that women develop a differential to obtain opportunities that are minimally closer to those granted to men in the world of work. Thus, as a movement of inestimable importance for the reduction of inequalities, it is urgent that society move forward in the sense that the professional demands that fall on women are the same that affect men, as well as the fair division of domestic tasks and the equal valuation of the workforce of both.

\section{Introdução}

No Brasil, a Constituição Federal de 1988 marca a ruptura com o regime autoritário instalado em 1964, simbolizando "o marco jurídico da transição democrática e da institucionalização dos direitos humanos no país" (PIOVESAN, 2008, p. 1). É denotado um avanço "extraordinário na consolidação dos direitos e garantias fundamentais, situando-se como o documento mais abrangente $e$ pormenorizado sobre os direitos humanos jamais adotado" (PIOVESAN, 2008, p. 2). Além disso, para Piovesan (2008), é a Carta de 1988 a que, dentre todas as Constituições brasileiras, mais assegurou a participação popular em seu processo de elaboração, uma vez que recebeu um número elevado de emendas populares, alargando, fortalecendo e aprimorando a proteção dos direitos políticos no território nacional.

Inúmeros foram os avanços constitucionais advindos das reinvindicações do movimento feminista no Brasil, sendo traduzidos no texto através de artigos que versam sobre a igualdade e a igualdade no âmbito familiar; o reconhecimento da união estável; o repúdio à violência doméstica; a igualdade entre filhos; o reconhecimento de direitos reprodutivos; a proibição da discriminação no mercado de trabalho e sua proteção especial, enfim, uma série de considerações que atingem as mulheres na garantia de seus direitos constitucionais, ampliadas por legislações posteriores, conforme explana Piovesan (2008).

"Pela primeira vez na história constitucional brasileira, consagra-se a igualdade entre homens e mulheres como um direito fundamental, nos termos do art. $5^{\circ}$, inciso I do texto" (PIOVESAN, 2008, p. 14). No âmbito jurídico, fica, assim, assegurada "a plena igualdade entre os gêneros no exercício dos direitos civis e políticos, sendo vedada qualquer discriminação contra a mulher" (PIOVESAN, 2008, p. 17).

Entretanto, há uma distância entre o avanço da legislação brasileira e a realidade das mulheres, persistindo, na cultura de nosso país, uma ótica sexista e discriminatória, impedindo-as ao exercício de seus direitos mais fundamentais com plena autonomia e dignidade (Piovesan, 2008). De acordo com o ranking do 
Relatório Global de Gênero (2021), elaborado pelo Fórum Econômico Mundial, numa de lista de 156 países, o Brasil ocupa, em 2021, o $93^{\circ}$ lugar numa análise que compara a lacuna de gênero na economia, política, educação e saúde.

O estudo do IBGE contendo estatísticas de gênero (2018) apresenta, em sua segunda versão, indicadores que confirmam uma desigualdade mensurável entre homens e mulheres na sociedade brasileira. Além da disparidade contundente entre elas e eles no mercado de trabalho, soma-se a isso o impacto dos afazeres domésticos e dos cuidados de pessoas de maior vulnerabilidade na soma do trabalho feminino (21,4 horas semanais de dedicação das mulheres contra 11,0 horas dos homens). Essa situação leva, também, a maior presença delas (1/3) nos trabalhos em tempo parcial ( 30 horas), que registram menores salários. Apesar de elas serem, no geral, mais instruídas que os homens, conforme registra a pesquisa, o rendimento das mulheres é, em média, $77,7 \%$ do montante delas, sendo que nos postos mais elevados, como nos cargos de diretoras/es e gerentes, elas recebem $61,9 \%$ do rendimento deles.

As informações dispostas podem ser analisadas sob as perspectivas dos estudos de Olinto (2011) e de Hirata e Kérgoat (2007), confirmando as teorias da segregação horizontal e da segregação vertical e a dos dois princípios organizadores da Divisão Sexual do Trabalho, respectivamente, sendo a seguir anunciados.

O primeiro princípio organizador, que é o da separação (Hirata e Kérgoat, 2007), anuncia que existem trabalhos de homens e trabalho de mulheres, assim como a segregação horizontal (Olinto, 2011) evidencia que a escolha profissional das mulheres é marcadamente diferente da dos homens. Em sua grande maioria, os caminhos profissionais das mulheres são direcionados para áreas e profissões hegemonicamente femininas, nas quais prevalecem a prestação de serviços, a organização, a limpeza, como um prolongamento das tarefas domésticas. Isso também é atestado pelo IBGE (2018).

Já o segundo, o princípio da hierarquia (Hirata e Kérgoat, 2007), diz que as atividades desenvolvidas por homens têm valor social e econômico superior às exercidas pelas mulheres e pode ser associado à segregação vertical (Olinto, 2011), denotando uma dificuldade maior para as mulheres ascenderem profissionalmente. Ressaltam-se também as inúmeras dificuldades enfrentadas por elas para se inserirem e se manterem no mercado de trabalho, sobretudo em áreas consideradas masculinas, o que Lima (2013) caracteriza como um labirinto de cristal.

Olinto (2011) evidencia as inúmeras conquistas atingidas pelas mulheres na educação e no trabalho, assim como sua crescente participação nas carreiras de ciência e tecnologia, evidenciando que elas estão rompendo estereótipos, enfrentando os preconceitos e discriminações e fazendo a sua própria história. Entretanto, apesar dos avanços, as crenças, os valores e as atitudes socialmente estabelecidos formam estereótipos sobre habilidades diferenciadas por sexo e influenciam as escolhas que as mulheres fazem e nas oportunidades que vão receber ao longo de toda a vida.

Este artigo versa sobre o que a literatura científica tem sugerido como uma das estratégias de resistência acionadas pelas mulheres frente à Divisão Sexual do Trabalho, especificamente discute-se o diferencial em relação a eles que as mulheres buscam - de maneira mais ou menos consciente - para que atinjam patamares mais próximos aos que os homens alcançam.

\section{Desenvolvimento}


Estratégias de resistência, no contexto de redutos profissionais tradicionalmente destinados aos homens e ocupados pelas mulheres, tal como defende Quirino (2011), diz respeito ao que elas fazem uso "para a sua inserção e permanência no mundo do trabalho" (QUIRINO, 2011, p. 38). Lombardi, por sua vez, faz uso da expressão "forma de resistência encontrada pelas mulheres" quando discute o objeto de estudo deste artigo: aquilo que elas acionam "visando romper as barreiras de gênero": "padrão de grande dedicação aos estudos e ao trabalho" (LOMBARDI, 2005, p. 169).

Essa é uma ideia importante no sentido de demonstrar que as mulheres não são passíveis frente às injustiças no mundo do trabalho. Ao contrário, "sofrem a ação das relações sociais, mas igualmente agem sobre elas, mobilizando, construindo, alterando, tanto individual como coletivamente, suas vidas, por meio das práticas sociais" (QUIRINO, 2011, p. 247). São, portanto, estratégias de luta (Quirino, 2011) e "fazem a dialética desses processos de manutenção e de transformar a realidade" (GONÇALVES, 2019, p. 99), visando "a síntese em direção a um mundo de equidade" (GONÇALVES, 2019, p. 102).

Dizer sobre a estratégia de resistência em questão é uma inferência dada a partir da pesquisa de campo do trabalho de dissertação de mestrado defendido por uma das autoras deste artigo (GONÇALVES, 2019), cuja sensibilidade do olhar enquanto pesquisadora já havia sido desperto por leituras anteriores que discutiam a temática de maneira tangencial (QUIRINO, 2011; LOMBARDI, 2005; SEGNINI, 1998; MESQUITA, 2017). Quando na escrita da evocada pesquisa, nomeamos esta estratégia como "ser mais para ser igual" (GONÇALVES, 2019) e, após a banca, recuperamos outras leituras que vão ao encontro do que aqui defendemos (LIMA, 2017; CARRILHO, 2016; BOSCHETTI, 2021).

Estes textos que nos amparamos argumentativamente são teses de doutorado sobre política de equidade em gênero e ciências no Brasil (LIMA, 2017), o trabalho feminino na Mineração (QUIRINO, 2011; CARRILHO, 2016) e na engenharia (LOMBARDI, 2005); dissertações de mestrado sobre a Divisão Sexual do Trabalho na engenharia (MESQUITA, 2017; GONÇALVES, 2019) e na Tecnologia da Informação (BOSCHETTI, 2021) e em um livro a respeito das mulheres bancárias (SEGNINI, 1998), todas pesquisas dialogando diretamente com a sociologia do trabalho francesa de base materialista. Esclarecemos que as pesquisas de Mesquita (2017), Gonçalves (2019) e Boschetti (2021) são dissertação do mestrado em Educação Tecnológica do CEFET-MG. Já o trabalho de Quirino (2011) e de Lombardi (2005), são teses de doutorado em educação - a primeira da UFMG e a segunda da UNICAMP; o de Carrilho (2016) é igualmente uma tese de doutorado, mas em Política Social, na UNB.

Justificamos a opção da escrita em primeira pessoa referenciando Veiga-Neto (2014), que tratando sobre a escrita acadêmica, tece considerações e sugestões a respeito da questão da autoria dizendo da pretensa neutralidade das Ciências Naturais recorrida, por vezes, nas Ciências Humanas. Essa "vontade de neutralidade [...] está ancorada no entendimento de inspiração positivista que acredita na possibilidade de o sujeito não contaminar - e não se deixar contaminar - pelo objeto estudado, descrito, problematizado" (VEIGA-NETO, 2014, p. 64). Assim, inspiradas pelo autor em questão, assume-se, nesta opção de escrita, que "tal isenção é uma ficção" (VEIGA-NETO, 2014, p. 64). 
No contexto da pesquisa de dissertação de mestrado (GONÇALVES, 2019), cinco estudantes do curso de Engenharia Mecânica do CEFET-MG foram entrevistadas em dias e horários previamente acordados, nas dependências da instituição. Uma delas, que recebeu, conforme preconiza a ética em pesquisa, um código alfanumérico de maneira a não ser possível sua identificação, é recorrida neste texto por ser a discente que mais evidencia o que se problematiza nesta proposta. Após a assinatura do Termo de Consentimento Livre e Esclarecido e do termo de cessão de fala, nós, autoras do texto e, nesse contexto recorrido, orientadora e mestranda em Educação Tecnológica, conduzimos uma entrevista com A1, que posteriormente foi transcrita e analisada pela então orientanda e compôs parte da pesquisa de campo da dissertação de mestrado defendida na presença de uma banca científica.

A1 é estudante que recorreremos para este recorte de estudo. Ela é discente do $6^{\circ}$ período e estava, quando na realização da entrevista, irregular no curso, fazendo disciplinas também do período anterior. A jovem de 21 anos tem um namorado, que também é aluno do curso de Engenharia Mecânica do CEFET-MG. Ambos participam do projeto de extensão da instituição denominado Fórmula Cefast, que tem como grande objetivo a competição Fórmula SAE Brasil, disputada nacionalmente entre alunos e alunas de engenharia, com os protótipos de corrida desenvolvidos pelas equipes participantes do evento. A1 possui um irmão biológico e, nas suas palavras, "três emprestados", sendo todos engenheiros de aeronave do ITA, uma reconhecida escola. O pai biológico e o que a criou também são engenheiros e sua mãe é técnica na área.

Quando questionada sobre ser possível conjugar seu sonho de ser mãe e de atingir o que ela pretende na vida profissional, A1 diz que "tudo que eu acho que eu não daria conta, quando chegou eu pego e dou um jeito e faço dar certo, entendeu?". Nesse contexto, ela cita a dificuldade de conciliar a atividade extensionista que exige muita dedicação com as matérias da graduação pela manhã e o curso de inglês e comenta: "é (sic) noites e noites viradas". Ainda sobre o Fórmula, A1 diz que o processo seletivo do projeto de extensão exige um projeto de trainee e o dela era o único individual, sendo também a única menina do grupo, realizando, portanto, todos os tipos de trabalho sem parceria. Nas palavras de A1, "eu fiz trabalho de homens também, eu peguei, eu lixei". Questionada se ela se referia aos trabalhos que exigem força, a estudante confirma dizendo "sim, furar um tubo com um aparelho de 165 é, tipo assim, brutal [...] até os meninos que eram mais fortes, que me orientaram, tem dificuldade de fazer o furo". Os diferenciais de A1, seja se dedicando durante a madrugada ou mesmo desempenhando bem funções que, no seu ponto de vista, não são fáceis aos homens, menos ainda às mulheres, são permanentemente recorridos em sua narrativa.

Lombardi, que também analisa o traço diferenciador do comportamento delas em relação ao grupo majoritário de homens, diz que esse é, portanto, um diferencial de gênero que visa "a afirmação por intermédio da grande dedicação aos estudos, de um excelente desempenho escolar, o qual mais tarde, no mercado de trabalho, será substituído pela necessidade da prova constante da competência profissional" (LOMBARDI, 2005, p. 168-169). Ana, 46 anos, engenheira metalúrgica formada em 1981 e entrevistada por Lombardi (2005) afirma que ela e outras duas colegas de sala "inflacionavam o desempenho de toda a turma" e que isso "vem de família, fui educada assim, tudo o que se faz tem que ser bem-feito" (LOMBARDI, 2005, p. 169 transcrevendo a fala de Ana, engenheira metalúrgica). Tal como A1, Ana também não visualiza que esta é uma estratégia mobilizada a fim de conseguir alguma 
equidade. Ambas citam que essa garra é uma característica pessoal, desenvolvida no seio familiar. Para Ana, se ela "tivesse feito Letras, teria tido o mesmo grau de dedicação" (LOMBARDI, 2005, p. 169 transcrevendo a fala de Ana, engenheira metalúrgica).

Pandora, codinome da "sujeita" de pesquisa da dissertação de mestrado Boschetti (2021), é uma mulher de 45 anos, graduada em Redes de Computadores e Administração de Redes de Computadores e possui 20 anos de experiência na sua área profissional. Ela se define como "aquela que faz o que ninguém quer fazer" (BOSCHETTI, 2021, p. 91 transcrevendo a fala de Pandora, que trabalha com Direito Digital) e "estuda muito para fazer o trabalho que fazia. Narra sobre se destacar buscando percorrer caminhos que não eram muito comuns" (BOSCHETTI, 2021, p. 141) e adiante, num próximo encontro entre a pesquisadora e Pandora, ela enfatiza o acúmulo de funções quando num cargo de liderança, a necessidade, citando Gonçalves (2019), de "ser mais para ser igual", já que, como analisa Boschetti, "não se espera de uma mulher traços agênticos e competência técnica" (BOSCHETTI, 2021, p. 143). A pesquisadora, que propõe uma interface entre a Divisão Sexual do Trabalho e a Ergonomia, reflete: "as narrativas de Pandora nos sugerem que jogar o jogo da vida remete à forma que encontrou de retrabalhar as normas e pertencer ao meio masculino do seu trabalho" (BOSCHETTI, 2021, p. 144).

Mesquita (2017) analisa a trajetória profissional de mulheres no exercício da engenharia numa interface com o hoje extinto Programa de Mobilidade Internacional nomeado de Ciências sem fronteiras (CsF) e confirma que em sua pesquisa, foi evidenciada a contribuição da experiência advinda do CsF "para a qualificação profissional das mulheres e um diferencial quando no momento da contratação" (MESQUITA, 2017, p. 7). Exemplo disso é admissão da engenheira de codinome Malu, que confirma a ênfase dada pelos recrutadores da vaga na experiência dela com o programa e acredita ter sido esse o fator determinante para sua escolha na seleção.

O pesquisador, ao analisar as falas de suas entrevistas, denuncia o "sexismo ainda presente nas engenharias" e ratifica "a necessidade constante das mulheres engenheiras reafirmarem sua capacidade e competência para exercer a profissão" (MESQUITA, 2017, p. 78). Mary, uma outra engenheira pesquisada por Mesquita (2017), diz que em sua sala, quando no início do curso, de 50 estudantes, apenas $10 \%$, ou seja, 5 , eram mulheres, um quantitativo muito mínimo. Após cinco anos de curso, o menor tempo para se concluir essa graduação, apenas 8 eram concluintes, formando, portanto, no tempo previsto. Desse seleto grupo de destaques acadêmicos, 3 eram mulheres, sendo uma delas única discente que se formou sem ter repetido uma matéria, o que, segundo, Mary, é um feito. Essa é uma fala que ilustra, portanto, o diferencial de dedicação e desempenho das mulheres.

Para A1, ela e suas colegas são tratadas pelos seus professores "até com mais respeito que os meninos". Sobre a causa disso, a estudante pontua desconforto na consideração, "mas a gente sabe quando a gente tem um nível de dedicação mais elevado que o outro [...] até os professores sabem que a gente é mais esforçada, que a gente tá lá persistindo". Adiante, ela diz que "nosso curso tem maioria homem, a maioria do povo do CEFET é ruim. As meninas normalmente são mais dedicadas, elas acabam "pegando o boi" por isso [...] eu sou porque a minha vida me exigiu". Essa fala de A1 se assemelha à de Dalva, engenheira civil formada 
em 1992 na PUC de campinas e doutoranda, no contexto da pesquisa de Lombardi (2005), na Poli. A "sujeita" de pesquisa da tese de doutorado Maria Rosa Lombardi revela que para se formar, "foi necessário enfrentar a resistência de parte do corpo docente, provar que era suficientemente esforçada para cobrir eventuais lacunas deixadas pelo seu curso de graduação e "perseverar" na busca de um orientador" (LOMBARDI, 2005, p. 160-161 analisando a fala de Dora, engenheira civil). Dora e $A 1$, para cursarem engenharia, precisaram desenvolver dois diferenciais em relação aos homens: dedicação mais elevada e perseverança no enfrentamento das dificuldades.

Granada, uma geóloga entrevistada da pesquisa de Carrilho (2016) no contexto da atividade mineradora, discorre sobre o perseverar no sentido relembrar sua aptidão para desenvolver uma tarefa tal como seu colega de cargo, um sujeito do sexo masculino, quando eventualmente se ausenta:

\begin{abstract}
Eu trabalho, faço a mesma função que um colega. E tem alguns técnicos, é uma cidade de interior, querendo ou não tem aquela mentalidade muito antiquada. Por exemplo, meu colega que faz a mesma coisa que eu, falta. Aí chegam essas pessoas que não aceitam ou que estão ali disfarçadamente meio que aceitando, 'cadê o fulano'? 'Fulano não veio, mas eu estou aqui para te ajudar'. 'Não, é só com ele mesmo, você não vai saber'. Eles sabem que eu e o fulano que faltou fazemos a mesma coisa, mas insistem em tirar dúvida, em dar satisfação, e fazer alguma coisa quando o outro colega está lá. Aí tenho que puxar, 'eu também faço isso aí, eu também sei fazer, me fala o que é'. Tem que estar lembrando toda hora. Aí depois que eu dou um puxão de orelha, aí ele fala que aconteceu isso, aí o colega que faltou, quando acontece isso resolve dessa maneira. Aí eu falo 'eu também sei resolver, vamos resolver'. Aí vou, resolvo. Tem um ou outro colega da equipe que a gente tem que estar lembrando toda hora (CARRILHO, 2016, p. 120 transcrevendo a fala de Granada, geóloga).
\end{abstract}

Essa necessidade de constantemente relembrar competência pode ser entendida, assim, como uma face da perseverança, sendo as mulheres "testadas e observadas constantemente na realização de suas funções" (CARRILHO, 2016, p. 120).

Apesar de não reconhecer mudanças pessoais exigidas por cursar uma graduação frequentada massivamente por homens ("eu não mudei nem um pouco para estar aqui"), percebeu-se, retomando Gonçalves (2019), que a estudante A1 mobiliza incontáveis estratégias para resistir e dar sequência ao sonho de, tal como os irmãos, numa casa cuja "criação é machista", ser uma engenheira mecânica bemsucedida. Ela precisou, portanto, aprender a conviver nesse contexto seguindo "as normais e regras vigentes", ainda que não explícitas, "mas da forma como as mulheres costumam fazer: trabalhando ou estudando muito, provando competência de forma persistente, com muita paciência" (LOMBARDI, 2005, p. 161). Nas palavras de Carrilho (2016, p. 119-120), "para ter alguma possibilidade de igualdade em um mesmo espaço, as mulheres têm que ser mais (competentes, escolarizadas, esforçadas), o que reforça a desigualdade".

Segnini (1998), analisando o contexto do trabalho bancário, dialoga com a ideia de que o padrão de dedicação das mulheres quanto ao estudo e ao trabalho é uma forma de romper as barreiras de gênero. As gerentes de banco estatal paulista confirmam, na pesquisa da autora, que precisam "mostrar mais" trabalho, ser mais eficiente e ter maior competência provada quando em comparação aos homens no sentido de serem aceitas no ambiente de trabalho. Essa também é a constatação de 
Mica, engenheira pesquisada por Carrilho (2016) quando na elaboração de sua tese de doutorado.

\begin{abstract}
A gente brinca que a mulher na Mineração tem que ter uma entrega muito superior aos homens. Uma entrega mediana do cara satisfaz, a da mulher eles vão querer trocar por outra pessoa. É uma sensação, eu não tenho nenhuma evidência de que isso é verdade, mas é uma sensação. Se você é mulher, se você é engenheira, se você exerce alguma profissão em uma área tão masculina, prepare-se porque você vai ser mais cobrada. Eles vão requerer mais de você. Tem uma conhecida minha que trabalha em mina também, em questão de progressão de carreira, crescimento profissional, ela já confidenciou que percebeu colegas que teoricamente eram mais incompetentes e ascenderam antes dela. Entraram depois dela, trabalham menos e hoje têm uma posição superior a dela, embora ela seja muito competente. Ela é engenheira, tem mestrado e tal. E ela é bonita, delicada e gentil. Ela pena. Porque aí os caras cantam, enchem o saco, e embora delicada, de vez em quando ela dá uma tirada nos caras e ainda assim misturam um pouco. Já melhorou muito, mas tem muito que melhorar (CARRILHO, 2016, p. 120 transcrevendo a fala de Mica, engenheira).
\end{abstract}

Mica visualiza essa situação do diferencial feminino no ofício de engenheira em mina. A percepção de Lazurita, codinome de uma técnica em mineração também entrevistada por Carrilho (2016), diz sobre as inúmeras barreiras que as mulheres precisam enfrentar ao longo da trajetória profissional (o "labirinto de cristal", de Lima (2013)) e conclui afirmando que as mulheres que alcançam o posto de trabalho almejado, que, no caso, é a de operadora de máquina, "elas têm um diferencial, de ser mais guerreira, de conseguir ser mais corajosa, ter essa força de vontade para pegar uma máquina daquele tamanho e operar" (CARRILHO, 2016, p. 112-113 transcrevendo Lazurita, técnica em mineração).

Anabelle Carrilho (2016) considerou que entre o grupo pesquisado de mulheres, era comum a definição de suas personalidades a partir de "comportamentos atribuídos à socialização dos homens": "se consideravam e eram percebidas por colegas e familiares como mais fortes, desbravadoras e determinadas que outras mulheres" (CARRILHO, 2016, p. 112). Nas palavras de Esmeralda, também "sujeita" de pesquisa da estudiosa, "toda vida o pessoal sempre me disse, nossa, você é 'abelhuda' demais, quer dizer que você é assim pra frente, sabe?" (CARRILHO, 2016, p. 112 transcrevendo a fala de Esmeralda, auxiliar de produção). Reflete-se no sentido de que "quando o que importa é o talento conjugado a esforço, em uma interpretação individual e liberal do sucesso, não há como inserir os argumentos históricos, sociais e culturais" (LIMA, 2017, p. 62).

Quirino, pesquisadora que também investiga a área da mineração em sua tese de doutorado, confirma que as "mulheres tendem a se qualificar ainda mais para entrarem no mercado de trabalho", no entanto, chama atenção para o fato disso não se reverter "em salários mais elevados ou em ocupações mais qualificadas que as masculinas, assim como não significa a desobrigação das responsabilidades domésticas e dos cuidados" (QUIRINO, 2011, p. 127). Ela, inclusive, nomeia como "superqualificação" ou, ainda, "formação profissional supérflua" o que encontrou nos perfis das mulheres na mineração de ferro. Também dizendo de problemas decorrentes do diferencial das mulheres, para Carrilho (2016, p. 120), "o sentimento de ser e comprovar mais, geralmente indireto, acaba por ser um mecanismo também de invisibilizar o trabalho das mulheres". 
Raquel Quirino cita um dos gerentes da empresa pesquisada dizendo que para ele, "a atuação das mulheres tem forçado os homens a buscar a melhoria de desempenho, ainda que isso seja contrário ao desejo deles" (QUIRINO, 2011, p. 253).

\begin{abstract}
Quando começamos a contratar as mulheres para a área operacional, parte da equipe recebeu mal, parte desconfiou e apenas uma parte muito pequena aceitou de imediato e até acharam que iria melhorar o setor. Estes superprotegiam as mulheres por carinho, os outros até faziam verdadeiras "sacanagens" com elas. As mulheres se defendiam ficando quietas no canto, outras queriam provar pra eles que eram tão boas de serviço quanto eles. E eu ficava de lado, só observando. Ignorava o conflito. Aos poucos eles foram vendo que elas vieram pra ficar e que não adianta reclamar. Hoje eu acho ótimo, porque para não ficar pra trás, eles estão tendo de correr e trabalhar tão bem quanto elas (QUIRINO, 2011, p. 253 transcrevendo a fala de GEOP, gerente).
\end{abstract}

Observa-se, a partir da fala de GEOP, tanta a questão discutida anteriormente quanto à necessidade de provar capacidade por parte das mulheres, quanto o diferencial feminino em termos de performance no trabalho.

\title{
3.Considerações finais
}

Apesar dos avanços constitucionais quanto aos direitos das mulheres no Brasil, as desigualdades persistem, validando os princípios organizadores da Divisão Sexual do Trabalho, referencial teórico que tem o trabalho e a sua materialidade como centro da discussão. No entanto, frente às crenças, valores e estereótipos que colocam as mulheres numa situação de desprestígio quando em comparação aos homens, elas têm mobilizado estratégias de resistência com vistas à equidade. Dessa forma, as mulheres demonstram que não são passíveis às injustiças que as atingem. Ao contrário, elas são ativas na construção de uma sociedade equânime.

Neste artigo, trabalhamos uma, dentre tantas, formas que as mulheres utilizam, de maneira mais ou menos consciente, de tornarem possível o caminho profissional almejado por elas. Quando em redutos tradicionalmente masculinos, este texto procurou um diálogo das entrevistadas de diferentes pesquisas de mestrado e de doutorado quando, em seus discursos, elas falam de uma estratégia comum: as mulheres resistem acionando padrões de estudo, de dedicação e de perseverança superiores aos dos que os homens precisam recorrer num mesmo contexto.

Essa situação é entendida como um movimento importante delas no sentido de que sejam rompidas as barreiras colocadas em função do gênero, tornando possível a entrada e permanência das mulheres nas áreas profissionais escolhidas. No entanto, é preciso que nós, enquanto sociedade, tenhamos avanços capazes de reverter a necessidade do diferencial feminino frente às oportunidades concedidas aos homens com um menor esforço, uma vez que essa situação reforça desigualdades.

\section{REFERÊNCIAS}

BOSCHETTI, Graciela de Andrade. Corpo-si sexuado? o que narram as mulheres da Tecnologia da Informação. Belo Horizonte, 2021. Dissertação (Mestrado em Educação Tecnológica) - Centro Federal de Educação Tecnológica de Minas Gerais. 
CARRILHO, Anabelle. Mulheres invisíveis, mas necessárias: a negação da Feminização no trabalho da Mineração. Brasília, 2016. Tese (Doutorado em Política Social) - Universidade de Brasília.

GONÇALVES, Bruna de Oliveira. Violência simbólica de gênero na engenharia: estudo de caso no CEFET-MG. Belo Horizonte, 2019. Dissertação (Mestrado em Educação Tecnológica) - Centro Federal de Educação Tecnológica de Minas Gerais.

HIRATA, Helena; KERGOAT, Daniele. Novas configurações da divisão sexual do trabalho. Cadernos de Pesquisa, v. 37, n. 132, p. 595-609, 2007.

IBGE. Estatística de Gênero: indicadores sociais das mulheres no Brasil. Rio de Janeiro; 2018.

LIMA, Betina Stefanello. O labirinto de cristal: as trajetórias das cientistas na física.

Estudos feministas, v. 21, n. 3, p. 883-903, 2013.

Lima, Betina Stefanello. Políticas de equidade em gênero e ciências no Brasil: avanços e desafios. São Paulo, 2017. Tese (Doutorado em Ciências Sociais) Universidade Estadual de Campinas.

LOMBARDI, Maria Rosa. Perseverança e resistência: a engenharia como profissão feminina. São Paulo, 2005. Tese (Doutorado em Educação) - Universidade Estadual de Campinas.

MESQUITA, Rodrigo Salera. Relações de gênero e Divisão Sexual do Trabalho na engenharia: interlocuções com o Programa Ciência sem Fronteiras. Belo Horizonte, 2017. Dissertação (Mestrado em Educação Tecnológica) - Centro Federal de Educação Tecnológica de Minas Gerais.

OLINTO, GILDA. A inclusão das mulheres nas carreiras de ciência e tecnologia no Brasil. Inc. Soc., v. 5, n. 1, p. 68-77.

PIOVESAN, Flávia. Igualdade de gênero na Constituição Federal: os direitos civis e políticos das mulheres no Brasil. In: DANTAS, Bruno et al. (Org.). Os alicerces da redemocratização. Brasília: Senado Federal/Instituto Legislativo Brasileiro, 2008.

QUIRINO, Raquel. Mineração também é lugar de mulher! desvendando a (nova?!) face da Divisão Sexual do Trabalho na Mineração de ferro. Belo Horizonte, 2011. Tese (Doutorado em Educação) - Universidade Federal de Minas Gerais.

SEGNINI, Liliana Rolfsen Petrilli. Mulheres no trabalho bancário. São Paulo: Edusp, 1998.

WORD ECONOMIC FORUM. Global gender gap report: insight report. Geneva; 2021. $405 f$. 